\title{
Bovine Papillomatosis in a One-Year-Old Kedah Kelantan Cross Cattle Calf
}

\author{
Mohammed Naji Odhah ${ }^{1,3^{*}}$, Jasni Sabri ${ }^{2}$, Mohd Farhan Hanif Reduan ${ }^{2}$, Bashiru Garba ${ }^{4}$, Siti Nor Che \\ Yahya $^{1}$, Eric Lim Teik Chung ${ }^{6}$, Siti Nurbakyah Khalid ${ }^{1}$, Faez Firdaus Abdullah Jesse ${ }^{5}$, Mohd Azam \\ Khan Gorimam ${ }^{2}$ and Nani Izreen $\mathrm{MS}^{2}$
}

\begin{abstract}
${ }^{1}$ Department of Veterinary Clinical Studies, Faculty of Veterinary Medicine, Universiti Malaysia Kelantan (UMK), Kampus Kota Locked Bag 36, Pengkalan Chepa, 16100, Kota Bharu, Kelantan, Malaysia; ${ }^{2}$ Department of Veterinary Paraclinical Studies, Faculty of Veterinary Medicine, Universiti Malaysia Kelantan, Pengkalan Chepa, 16100 Kota Bharu, Kelantan, Malaysia; ${ }^{3}$ Department of Public health, Faculty of Veterinary Medicine, Thamar University, 87246 Dhamar, Yemen; ${ }^{4}$ Department of Veterinary Public Health \& Preventive Medicine, Faculty of Veterinary Medicine, Usmanu Danfodiyo University, Sokoto, Nigeria; ${ }^{5}$ Department of Veterinary Clinical Studies, Faculty of Veterinary Medicine, Universiti Putra Malaysia, 43400 UPM Serdang, Selangor; ${ }^{6}$ Department of Animal Science, Faculty of Agriculture, Universiti Putra Malaysia, 43400 UPM Serdang, Selangor, Malaysia

*Corresponding author: naji.ao@umk.edu.my
\end{abstract}

Article History: 20-222 Received: 23-Oct-2020 Revised: 28-Dec-2020 Accepted: 01-Jan-2021
ABSTRA C T
Bovine papillomatosis is an infectious disease, characterized by the presence of multiple benign mass that can regress
spontaneously or progress into malignant neoplasia caused by bovine papillomavirus. Epidermal proliferation causes
the lesion to have the keratotic surface that resembles a cauliflower. In this case report, bovine papillomatosis that was
encountered in a farm at UMK Bachok, Kelantan will be discussed. A year-old male Kedah Kelantan (KK) cross cattle
calf was presented with a presence of multiple, circular, around 1-2cm in diameter, wart-like lesion localized on the
ventral part of the mandible and on the chin. A series of diagnostic approaches had been conducted to reach the definitive
diagnosis, which includes biopsy for histopathology, polymerase chain reaction (PCR) and fecal examination.

Key words: Bovine papillomatosis, Wart, Cauliflower-like lesion, Autogenous vaccine

(C202I IJVS - All Rights Reserved

\section{INTRODUCTION}

Bovine papillomatosis is an infectious, contagious and a neoplastic disease, which is characterized by the presence of multiple benign masses (papilloma) on the integument that can regress spontaneously or progress into malignant neoplasia (Araldi et al. 2015). In cattle, papilloma (also called warts), are most commonly found on the head, neck shoulder and occasionally on the back and abdomen. The lesions also have a keratotic surface due to epidermal proliferation that resembles a cauliflower (AL-Salihi et al. 2020); Timurkan and Alcigir 2017). Warts or papilloma would appear like a cauliflower, dry and rough in appearance. It usually would have different shapes and sizes and varies in color; in the shade of grey to black and it can be either be solitary in one place one or multiple (ALSalihi et al. 2020).

It is caused by bovine papillomavirus (BPV) belonging to the family of Papillomaviridae. There are 15 different types of bovine papillomavirus that have been identified, and they are classified in 4 different subgroups which are deltapapillomavirus, xipapilomavirus, epsilonpapillomavirus and dyoxipapilomavirus (Maeda et al. 2007). The classification was based on the homology within the genomic regions of L1 major capsid protein and characteristic phylogenetic analysis. BPV 1, 2, 13, and 14 in the delta class were associated with fibropapilloma (Araldi et al. 2017). BPV 3, 4, 6, 9, 10, 11, and 12 in XI class were purely epitheliotropic where they are associate with cutaneous papilloma. BPV 5 and 8 in epsilon class share some similarities with the former two groups. BPV 7 in dyoxi class is a newly found type. Papilloma or warts can occur anywhere on the body of an animal (Lyon 2011). It can be on the head, the muzzle, the limbs, the neck, as well as on the ventral part of the body (Sundberg 1987). A topography study was done by Jana and Mukherjee (2012) where wart most commonly found on the anterior part of the body was $52.25 \%$, followed by posterior $(32.50 \%)$, anteroposterior $(12.01 \%)$ and the whole body $(3.84 \%)$.

Cite This Article as: Odhah MN, Sabri J, Reduan MFH, Garba B, Yahya SNC, Chung ELT, Khalid SN, Jesse FFA, Gorimam MAK and Izreen MSN, 2021. Bovine papillomatosis in a one-year-old Kedah Kelantan cross cattle calf. International Journal of Veterinary Science 10(3): 240-243. https://doi.org/10.47278/journal.ijvs/2021.037 
Int J Vet Sci, 2021, 10(3): 240-243.

\section{Clinical History}

Janggut is a one-year-old male Kedah-Kelantan cross cattle that weighed around $200 \mathrm{~kg}$ with a body condition score of 3.5 and was manage extensively. The farm visit was on April 2018 for a routine deworming session. There were 23 other cattle that were also raised extensively. As for Janggut and this case was an incidental finding. Upon physical examination, Janggut appears alert and responsive; his pulse, respiratory rate and temperature were all within the normal range. The mucous membrane was moist and pink, and there was no enlargement involving the lymph nodes. On the integumentary system, there was the presence of a wart-like lesion on the ventral side to the mandible and on the chin (Fig. 1).

Based on the lesions, papillomatosis and parapoxvirus infection were ruled in as differential diagnosis. Also, Fig. 1 showed a presence of multiple, circular, around $1-2 \mathrm{~cm}$ in diameter, wart-like lesion localized on the ventral part of the mandible and on the chin.

\section{Diagnosis}

On clinical examination, when the lesions are multiple, and appear as a circular warty pedunculated brownish keratinized lesion, they may be sufficient and characteristic enough to confirm the diagnosis as papillomatosis. However, a further test is needed to confirm the diagnosis.

A biopsy on the wart was taken and fixed in a $10 \%$ formalin and sent for histopathological analysis. On the lowest magnification view, there was a well develop fingerlike projecting papillae (Fig. 2a). Similarly, Fig. 2b shows hyper parakeratosis where there is the hyperplasia of the stratum while retaining their nuclei (double yellow arrowhead) while on the double black arrowhead, indicate acanthosis as shown by hyperplasia of the stratum spinosum with elongated rete pegs. Rete pegs are the epithelial extensions that project into the underlying connective tissue in the skin. Furthermore, the red asterisk, there is ballooning degeneration of the keratinocyte and on the yellow arrow shows giant clumped pleomorphic keratohyalin granules. This condition is known as koilocytosis (Fig. 2c). There was also marked hyperplasia of stratum granulosum with prominent basophilic keratohyalin granules (Fig. 2d). Koilocytosis is a diagnostic marker for papillomavirus infection and can be observed morphologically in histological sections (Fig. 2).

In addition to the histopathology, a polymerase chain reaction (PCR) was conducted after viral DNA was amplified by PCR assays using Promega Master Mix kit according to the instructions of the manufacturer. This was achieved by screening for the presence of BPV DNA using the FAP59/64 consensus primers followed by amplification using BPV type-specific primers (BPV2-5and 8-10 for skin lesions; Carvalho et al. 2012). The result came out positive for papillomavirus and negative for parapoxvirus based on the positive and negative controls. There was no significant finding on the fecal examination. Based on the diagnostic workup done, parapoxvirus was ruled out as the PCR result is negative. Thus, a tentative diagnosis that can be deduced is papillomatosis based on the histopathology and also PCR result. The prognosis for this case is good as bovine papillomatosis is a self-limiting disease. Meaning that with time, usually takes up in months, the lesion will regress by its own. As in this case, the animal showed no systemic problem and was eating and drinking well.

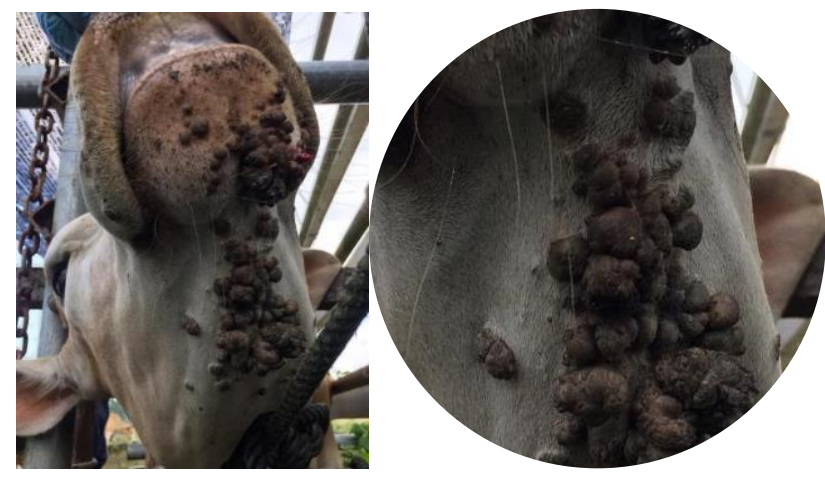

Fig. 1: Papillomavirus lesions in the cow showing multiple lesions on the ventral side to the mandible and the chin wall.

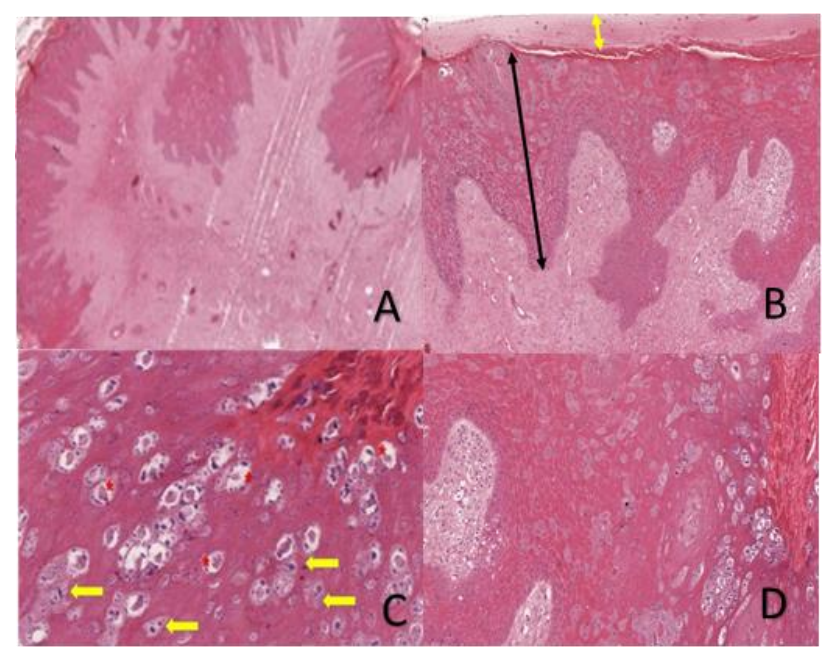

Fig. 2: Histology section of warts. A photomicrograph of papilloma in a cattle calf. H \& E Stain, 100X (A \& B) and 400X (C \& D).

\section{Treatment}

Treatment approach was by giving the autogenous vaccine at $5 \mathrm{ml}$ subcutaneously and revaccinated at seven days' intervals for four weeks. Briefly, the papilloma lesions were excised, finely ground and then filtered after resuspension in normal saline. Subsequently, the filtrate was treated with $0.5 \mathrm{ml}$ of $10 \%$ formaldehyde in order to inactivate the virus. Finally, streptomycin-penicillin at $2 \mathrm{mg} / \mathrm{ml}$ was added and stored in the refrigerator until required (Mayilkumar et al. 2014).

\section{Client Education}

The client was educated on the need to isolate the animal from the rest of the herd to stop the spread of the disease. He was also advised to disinfect the pens and equipment used with a $2-4 \%$ formaldehyde solution. Improve feeding by giving more pasture and added molasses to increase the appetite of the cattle. Vaccinate remaining cows from the same herd with the prepared autogenous vaccine.

\section{DISCUSSION}

Bovine papillomavirus is a double-stranded, nonenvelope DNA virus. It is strictly species-specific with the exception of BPV 3, which can cross species causing sarcoid in equine. Pathogenesis, start when the virus is able 
to enter the skin when there is microabrasion on the skin (Lunardi et al. 2013). The virus enters and infects the keratinocyte of the stratum basale. Then the virus amplifies, the basal keratinocyte at stratum basale undergo differentiation. This leads to the expression of viral protein that can stimulate cell growth (Stanley 2012). It results in hyperproliferation of the stratum spinosum and stratum granulosum. The hyperproliferation caused the formation of the exophytic mass, which is warts as a consequence of the acanthosis (Araldi et al. 2017). The hyperproliferation also causes the keratinization process to occur. The histological slides were characterized by the increase of the keratin granules in the granular layer. Then the virus will assemble in the most differentiated epithelium and the virion will be released via cell degeneration resulting in koilocyte formation that will later lead to cell apoptosis or cell death (Krawczyk et al. 2008).

There are several treatment options that have been reported, such as autohemotherapy, autogenous vaccine and surgical excision. A study by Kavithaa et al. (2014) state that autohemotherapy was found to be the most effective therapy to cure papillomatosis. The procedure to perform this therapy is first, by taking blood from the jugular vein using an $18 \mathrm{G}$ hypodermic needle and syringe. After that, the blood will be injected back intramuscularly. This treatment is repeated at weekly interval for four weeks continuously (Nehru et al. 2017). The mechanism behind it is when the blood is re-injected back to the animal, it carries the fragment of viral particle and makes its way into the immune networks and the body produce appropriate antibodies (AL-Salihi et al. 2020).

For the autogenous vaccine, the procedure is by taking warts and put into normal saline and filter it, after that $10 \%$ formalin and antibiotic is added and were left overnight. After that, the vaccine is ready to be used (Lesnik et al. 1999). A similar principle is used in the autogenous vaccine with the autohemotherapy where the body produce antibody through a series of an immune response (Turk et al. 2005). Removal by surgical excision is not recommended because it may lead to recurrence and stimulation of growth of the warts. However, it can be done when the warts are solitary, mass size $>5 \mathrm{~cm}$, small in number and when it near their maximum size or when regressing. In most cases, there are too many warts for surgical removal (Carvalho et al. 2016).

Bovine papillomatosis causes significant economic losses due to the associated growth retardation, weight loss, and decreased milk production in BPV-infected animals (Grindatto et al. 2015). For example, when the papillomatosis occurs at the teat/udder area, this will cause reduced milk production, the calf cannot suckle resulting in growth retardation for the calf, also the infection can occur when warts sloughed off and become a source of infection that cause mastitis (Grindatto et al. 2015). When warts occur on the mouth area, the cattle will lose weight due to reduced appetite and cause growth retardation. All of this will have an impact directly to the farmers (Araldi et al. 2017). The morbidity in this condition is high while there is a low mortality rate. However, both of these can cause economic loss (Araldi et al. 2017).

Control and prevention are important to help in reducing the loss faced by the farmers. As common as its sound "prevention is better than cure". The commercial vaccine is used as prophylaxis, and the autogenous vaccine is used as a treatment. The autogenous vaccine is stated to be more effective than those commercially available (Turk et al. 2005). It is recommended to begin vaccination in calves as early as 4-6 weeks of age in the herd where this disease is circulating with a dose of about $0.4 \mathrm{ml}$. intradermally given at two sites. The vaccination is repeated within four to six weeks and at one year of age. Disinfect the equipment application inert material surrounding the animal with 4-6\% formaldehyde to kill the virus that are persistent in the environment (Suveges and Schmidt, 2003; Turk et al. 2005). Disinfect also, instruments used while doing procedure such as dehorning, tagging, tattooing, milking between animals. Lastly, isolate the affected animal separately from the herd. As this disease is a contagious disease, it can easily be transmitted to other naïve cattle (Turk et al. 2005).

In conclusion, Janggut was positively diagnosed with bovine papillomatosis based on clinical signs, histopathology and polymerase chain reaction. The autogenous vaccine was given as treatment to stimulate the immune system to produce an antibody against the virus.

\section{Acknowledgement}

The authors would like to acknowledge the Veterinary Officers of UMK Veterinary Clinic and laboratory staff of Histopathology and Molecular, Faculty of Veterinary Medicine, Universiti Malaysia Kelantan for their technical assistance during the time of handling this case.

\section{Funding}

This research did not receive any specific grant from funding agencies in the public, commercial, or not-forprofit sectors.

\section{Authors Contribution}

MNO, JS and MFHR, managed the case at the clinic, ELTC, SNCY, worked together to produce the autogenous vaccine, MAKG, NIMS conducted the histopathology and interpretation of the slides, MNO, BG, SNK, FFAJ produced the initial manuscript draft. All authors revised and granted approval for the final draft submission to the journal.

\section{REFERENCES}

AL-Salihi KA, Al-Dabhawi AH, Ajeel AA, Erzuki IA and Ali TAH, 2020. Clinico-Histopathological and immunohistochemical study of ruminant's cutaneous papillomavirus in Iraq. Veterinary Medicine International 2020: 1-11. https://doi.org/10.1155/2020/5691974

Araldi R, Melo T, Neves A, Spadacci-Morena D, Magnelli R, Modolo D and Beçak W, 2015. Hyperproliferative action of bovine papillomavirus: genetic and histopathological aspects. Genetics and Molecular Research 14: 12942-12954. https://doi.org/10.4238/2015.October.21.15

Araldi RP, Assaf SMR, Carvalho RF, Carvalho MAC, Souza JM, Magnelli RF and Beçak W, 2017. Papillomaviruses: a systematic review. Genetics and Molecular Biology 40: 121. https://doi.org/10.1590/1678-4685-GMB-2016-0128

Carvalho R, Araldi R, Lima T, Modolo D, Souza J and Beçak W, 2016. Synergic associations between the bovine papillomavirus infection and alimentary cofactors. Reference Module in Food Bioscience 2016: 1-10. https://doi.org/10.1016/B978-0-08-100596-5.21138-4 
Carvalho CCR, Batista MVA, Silva MAR, Balbino VQ and Freitas AC, 2012. Detection of bovine papillomavirus types, co-infection and a putative new BPV11 subtype in cattle. Transboundary and Emerging Diseases 59: 441-447. https://doi.org/10.1111/j.1865-1682.2011.01296.x

Grindatto A, Ferraro G, Varello K, Crescio MI, Miceli I, Bozzetta E and Nappi R, 2015. Molecular and histological characterization of bovine papillomavirus in North West Italy. Veterinary Microbiology 180: 113-117. https://doi.org/ 10.1016/j.vetmic.2015.08.001

Jana D and Mukherjee SK, 2012. Management of bovine cutaneous papillomatosis with ivermectin in farm bred calf crops of West Bengal. Indian Journal of Field Veterinarians 8: 69-71.

Kavithaa N, Rajkumar NV and Jiji R, 2014. Papillomatosis in jersey cows and its different medical treatment. International Journal of Science, Environment and Technology 3: 692-694.

Krawczyk E, Suprynowicz FA, Liu X, Dai Y, Hartmann DP, Hanover J and Schlegel R, 2008. Koilocytosis: a cooperative interaction between the human papillomavirus E5 and E6 oncoproteins. The American Journal of Pathology 173: 682688. https://doi.org/10.2353/ajpath.2008.080280

Lesnik F, Bires J, Suli J, Korim P, Posivak J, Mattova J and Levkut M, 1999. Autovaccination and metabolic profiles at bovine papillomatosis. Slovensky Veterinarsky Casopis (Slovak Republic) 24: 290-294.

Lunardi M, de Alcântara BK, Otonel RAA, Rodrigues WB, Alfieri AF and Alfieri AA, 2013. Bovine papillomavirus type 13 DNA in equine sarcoids. Journal of Clinical Microbiology 51: 2167-2171. https://doi.org/10.1128/JCM. 00371-13

Maeda Y, Shibahara T, Wada Y, Kadota K, Kanno T, Uchida I and Hatama S, 2007. An outbreak of teat papillomatosis in cattle caused by bovine papilloma virus (BPV) type 6 and unclassified BPVs. Veterinary Microbiology 121: 242-248. https://doi.org/10.1016/j.vetmic.2006.12.015

Mayilkumar K, Kokila S, Manimuthu P and Kuppusamy G, 2014. Formalin inactivated autogenous vaccine for treatment of papillomatosis in adult dairy cow. Indian Journal of Veterinary Pathology 91: 13-15.

Nehru A, Sunandhadevi S, Rama T and Muniyappan N, 2017. Efficacy of auto-hemotherapy in bovine teat papillomatosis: A case report. Advances in Animal and Veterinary Sciences 5: 350. https://doi.org/10.17582/journal.aavs/2017/5.8.350. $\underline{351}$

Lyon F, 1994. IARC Monographs on the Evaluation of Carcinogenic Risks to Humans. Some Industrial Chemicals 60: 389-433.

Stanley MA, 2012. Epithelial cell responses to infection with human papillomavirus. Clinical Microbiology Reviews 25: 215-222. https://doi.org/10.1128/CMR.05028-11

Sundberg J, 1987. Papillomavirus infections in animals. In: Papillomaviruses and Human Disease, Springer, pp: 40-103.

Suveges T, and Schmidt J, 2003. Newer data on the occurrence in Hungary of, losses caused by and ways of control of bovine papillomatosis. Magyar Állatorvosok Lapja 125: 83-87.

Timurkan MO, and Alcigir ME, 2017. Phylogenetic analysis of a partial L1 gene from bovine papillomavirus type 1 isolated from naturally occurring papilloma cases in the northwestern region of Turkey. Onderstepoort Journal of Veterinary Research 84: 1-6. https://doi.org/10.4102/ojvr.v84i1.1450

Turk N, Zupancic Z, Staresina V, Kovac S, Babic T, Kreszinger M, Milas Z, 2005. Severe bovine papillomatosis: detection of bovine papillomavirus in tumour tissue and efficacy of treatment using autogenous vaccine and parammunity inducer. Veterinarski Arhiv 75: 391-397 